\title{
Minimally invasive esophagectomy: A treatment modality for esophageal cancers in Pakistan - A case series
}

\author{
Sameer Ur Rehman, Abid Jamal
}

\begin{abstract}
Introduction: There is an increase in incidence of esophageal cancers in Pakistan, particularly squamous cell cancer, due to a rise in tobacco use in different forms. Possibly, the only therapeutic option for esophageal cancers, to date, is the use of neoadjuvant chemotherapy followed by surgical esophageal resection. Case Series: For the very first time, we report fives cases in Pakistan where Minimally Invasive Esophagectomy was adopted as a treatment modality for the management of esophageal cancers. Conclusion: Open esophageal resection has a high morbidity and mortality. In addition, it involves long Intensive Care Unit stay, in-hospital stay and long recovery period. Minimally invasive esophagectomy seems to have the potential to improve this, if employed frequently in the management of esophageal cancers. Based on our initial experience of Minimally Invasive Esophagectomy, videoscopic esophagectomy appears to be as safe as conventional open esophagectomy with the potential to achieve better post-operative results.
\end{abstract}

Sameer Ur Rehman ${ }^{1}$, Abid Jamal ${ }^{2}$

Affiliations: ${ }^{1}$ Final Year Medical Student, Medical College, Aga Khan University, Karachi, Pakistan;

${ }^{2}$ General Surgeon, Minimal Access and Laparoscopic Surgery, Patel Hospital, Karachi, Pakistan

Corresponding Author: Dr. Abid Jamal, Department of General Surgery, Patel Hospital, ST-18, Block-4, Gulshan-e-lqbal, Karachi - 75300, Pakistan; Phone009221-34541317; Email: abidjamal@excite.com

Received: 30 April 2011

Accepted: 21 July 2011

Published: 01 September 2011
Keywords: Esophagus, Cancer, Surgery, Minimally invasive surgery, Esophagectomy

$* * * * * * * * *$

Rehman SU, Jamal A. Minimally invasive esophagectomy: A treatment modality for esophageal cancers in Pakistan- A case series. International Journal of Case Reports and Images 2011;2(9):5-8.

$* * * * * * * * *$

doi:10.5348/ijcri-2011-09-52-CS-2

\section{INTRODUCTION}

Esophageal cancer ranks among ten most prevalent cancers and the sixth most common cause of cancer deaths worldwide [1]. This malignancy seems to be relatively more common in Pakistan with data showing a high prevalence of esophageal cancers in Karachi [2]. Surgery is the cornerstone for esophageal cancer treatment. In a very short period of time minimally invasive surgery (MIS) has revolutionized the management of surgical disorders. It has shifted the focus of surgery towards reducing the morbidity and mortality without compromising on the quality of healthcare. Esophagectomy has traditionally been performed by open methods. Minimally Invasive Esophagectomy (MIE) is now a commonly employed treatment modality in the west as opposed to open esophagectomy in our country; with studies reporting a lower mortality rate and shorter hospital stay in videoscopic methods [3-4]. We present fives cases of esophageal cancers in Pakistan where MIE was adopted as a treatment modality. To the best of our knowledge, this is the first ever reported case series on MIE from Pakistan. 


\section{METHOD}

Five cases of esophageal cancers in which MIE was done were followed carefully both pre and postoperatively during the period from August 2010 to February 2011. All the information regarding these cases was extracted from their medical records after taking informed consent from the patients.

\section{CASE SERIES}

Patient 1: A 38-year-old female patient presented with progressive dysphagia for six months. CT scan was done which showed T3No stage esophageal cancer (Figure 1). Diagnostic endoscopy revealed juxtracarinal esophageal lesion which proved to be squamous cell carcinoma on biopsy (Figure 2). The patient was planned for a minimally invasive resection of the esophageal cancer with gastric tube construction. Abdominal part of the surgery was done videoscopically, thoracic part was done by open method due to dense juxtra-carinal adhesions. Eight lymph nodes were resected in the procedure and clear margins were obtained. The operative time was eleven hours, ICU stay of two days and hospital stay of nine days with no immediate post-operative complications. The patient did well in the initial post-operative period but eventually expired at a follow up of five months due to recurrent disease.

Patient 2: A 32-year-old female presented with complaints of odynophagia and heart burn for past two months. Workup for these complaints was done which revealed T2No gastroesophageal junction squamous cell carcinoma. MIE was planned for the resection of the tumor. Both abdominal and thoracic parts of the operation were done successfully by videoscopic approach. The position of the patient and the ports used for the camera and instrumentation are shown in figure 3 . The operative time for the procedure was 10 hours, ICU stay of two days and hospital stay of nine days with unremarkable post-operative period. The procedure was done with 33 lymph node resections and clear margins were obtained. The patient is alive and healthy at a follow up of nine months. This was probably the first time a totally videoscopic esophagectomy was successfully carried out in Pakistan.

Patient 3: A 54-year-old female presented with complaints of severe progressive dysphagia, nausea and vomiting for last 3-4 months. Computed tomography (CT) scan and endoscopy with biopsy reveled T3No squamous cell carcinoma. The patient was planned for a Minimally Invasive Esophagectomy. The operation was carried out successfully with 25 lymph node resections and clear margins. The operative time was six and a half hours. The patient had an extended ICU stay of 21 days and a hospital stay of 30 days due to anastomotic leak and thoracic duct leakage which eventually resolved on NPO and total

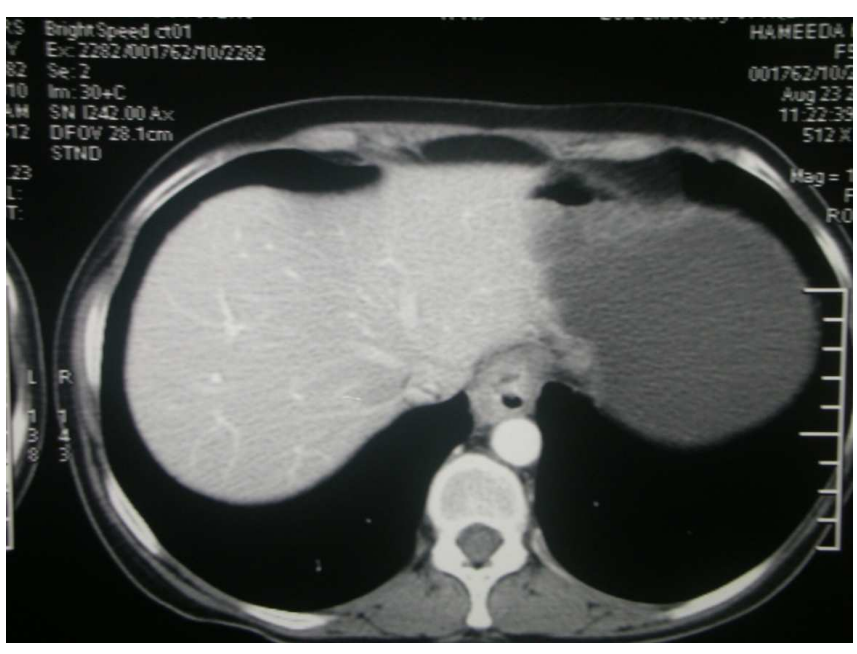

Figure 1: Computed tomography scan showing thickened esophageal margins.

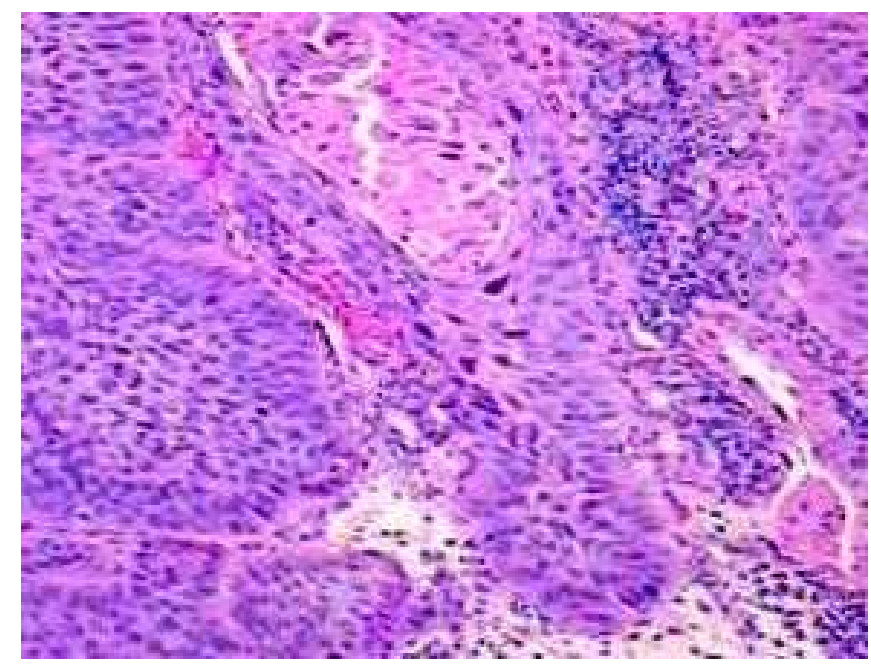

Figure 2: Photomicrograph showing squamous cell carcinoma of the esophagus. (H\&E, x2OO)

parenteral nutrition. The patient is doing fine at follow-up of seven months now. A still picture from videoscopic procedure showing division of left gastric pedicel (left) and esophageal mobilization (right) is shown in figure 4.

Patient 4: A 61-year-old female, a diagnosed case of distal esophageal adenocarcinoma on biopsy came to the clinic for the surgical management. CT scan was done and disease was staged to be T3No. The patient was scheduled for a Minimally Invasive Esophagectomy. The procedure was completed in 10 hours with clear margins and 12 lymph node resections. There were no operative complications and the patient was discharged from the hospital on the $11^{\text {th }}$ post operative day. The patient is alive, healthy and disease free at a follow up of three months.

Patient 5: A 51-year-old male presented to the 


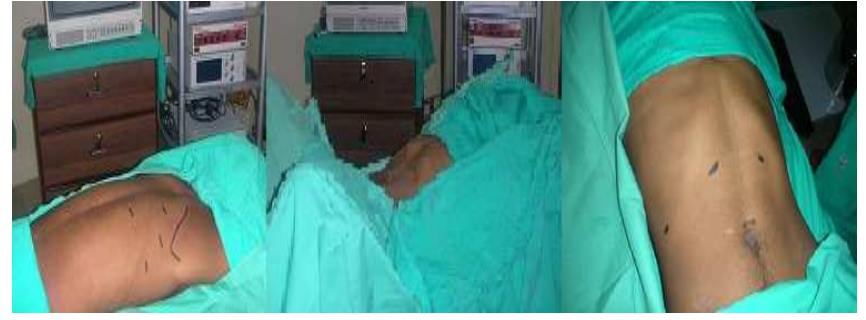

Figure 3: Position of the patient and videoscopic ports thoracoscopic postion (left), laparoscopic position (middle), laparoscopic ports (right).

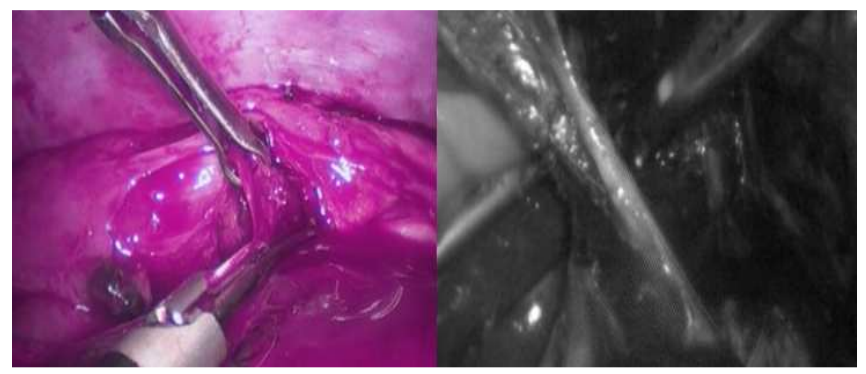

Figure 4: Videoscopic clip picture - division of left gastric pedicel (left), circumferential esophageal mobilization (right).

the clinic with complaints of progressive odynophagia and recurrent vomiting on and off for a period of five months. Endoscopicc biopsy revealed distal squamous cell carcinoma. CT scan revealed tumor involving lower esophagus, staged T3No. MIE was done with an operative time of nine hours. Patient was placed in supine position for the thoracoscopic part of the operation. Modified lithotomy position was used for the laproscopic part (Figure 3). The surgery was done with with clear margins and 18 lymph nodes were resected. The patient had a pleural effusion postoperatively which was managed conservatively. After a hospital stay of 12 days the patient was discharged. The patient remains to be healthy and disease free at a follow up of two months.

\section{DISCUSSION}

Since the start of the 1990s, the use of Minimally Invasive Esophagectomy instead of the open technique has increased in the western world. The minimally invasive procedures for esophagectomy have been recommended to reduce operative trauma and complications secondary to the large incisions and pain of open surgery. These procedures have been associated with earlier and better return to normal respiratory function and ambulation, without detriment to the 5-year survival rate. Endoscopic dissection was first reported in Germany by Bumm et al. [5], who used a special mediastinoscope for the trans-hiatal approach.

As with other laparoscopic operations for cancer, concern has been raised about port-site cancer recurrence, adequacy of surgical margins, and an adequate number of lymph node resections. In our initial experience with videoscopic esophagectomy in Pakistan, one out of five cases had mortality because of recurrent disease at a follow-up of five months. All of the cases were operated with clear margins with appropriate lymph node dissection in almost all cases. Only one of the five cases had a post-operative anastomotic leak which self-resolved on total parenteral nutrition. The operative time ranged from 6.5 hrs to $11 \mathrm{hrs}$ and the mean hospital stay was 14.2 days.

The debate of MIE as opposed to open esophagectomy is well answered by the largest series of total Minimally Invasive Esophagectomy reported by Luketich et al. who reported a lower mortality rate (1.4\%) and shorter hospital stay (seven days) than most open series. The use of MIE in England is also increasing exponentially. There was a suggestion that patients undergoing MIE had better 1-year survival rates than patients undergoing open esophagectomy $(\mathrm{OR}=0.68,95 \% \mathrm{CI}=0.46-1.01, \mathrm{p}=0.058)[6]$.

Videoscopic esophagectomy is technically feasible and safe in experienced hands [7]. The completeness of mediastinal lymphadenectomy is comparable to that of the open technique but with less significant pulmonary decline compared to thoracotomy [8]. Perioperative morbidity and mortality also seem to be lower for the minimally invasive technique and the social reinsertion with return to normal activities is shortened. Thoracoscopic and laparoscopic esophagectomy offers better visual control, with better definition and accuracy for the mediastinal dissection. It avoids major complications such as recurrent nerve damage, mediastinal bleeding, chylothorax, great vessel damage, tracheal damage and tumor rupture during dissection. This approach is not associated with severe hemodynamic changes secondary to cardiac compression during blind dissection, and therefore offers a decrease in operative trauma [9].

\section{CONCLUSION}

Based on our initial experience of MIE in Pakistan, Minimally Invasive Esophagectomy appears to be as safe as conventional open esophagectomy. Applications of thoracoscopy and laparoscopy to esophagectomy eliminate the thoracotomy and laparotomy incisions and therefore further reduce operative trauma and enhance postoperative recovery. The intraoperative complications are minimal, and the postoperative complications are less than with the blind technique. The anastomotic leakage at the cervical level is not dependent on the approach used. For us, this does not represent a severe complication 
because it often is self-limited.

$* * * * * * * * *$

\section{Author Contributions}

Sameer Ur Rehman - Substantial contributions to conception and design, Analysis and interpretation of data, Drafting the article, Revising it critically for important intellectual content; Final approval of the version to be published

Abid Jamal - Substantial contributions to conception and design, Drafting the article, Revising it critically for important intellectual content, Final approval of the version to be published

\section{Guarantor}

The corresponding author is the guarantor of submission.

\section{Conflict of Interest}

Authors declare no conflict of interest.

\section{Copyright}

(C) Sameer Ur Rehman et al. 2011; This article is distributed under the terms of Creative Commons attribution 3.0 License which permits unrestricted use, distribution and reproduction in any means provided the original authors and original publisher are properly credited. (Please see www.ijcasereportsandimages.com /copyright-policy.php for more information.)

\section{REFERENCES}

1. Blot WJ. Epidemiology and genesis of esophageal cancer. In Roth JA, Ruckdeschel JC, Weisenburger TH (eds): Thoracic Oncology. Philadelphia, PA: Saunders. 1995;278.

2. Bhurgri Y. Epidemiology of Cancers in Karachi (1995-1999). Pharmacia \& Upjohn, Unique Printers, Karachi, Pakistan 2001;23-46.

3. Luketich JD, Alvelo-Rivera M, Buenaventura PO, Christie NA, McCaughan JS, Litle VR, Schauer PR, Close JM, Fernando HC. Minimally invasive esophagectomy: outcomes in 222 patients. Ann Surg. 2003 Oct;238(4):486-94; discussion 494-5.

4. Nguyen NT, Hinojosa MW, Smith BR, Chang KJ, Gray J, Hoyt D. Minimally invasive esophagectomy: lessons learned from 104 operations. Ann Surg. 2008 Dec;248(6):1081-91.

5. Bumm R, Feussner H, Bartels H, et al. Radical transhiatal esophagectomy with two-field lymphadenectomy and endodissection for distal esophageal adenocarcinoma. World J Surg. 1997 Oct;21(8):822-31.

6. Lazzarino AI, Nagpal K, Bottle A, Faiz O, Moorthy K, Aylin P. Open versus minimally invasive esophagectomy: trends of utilization and associated outcomes in England. Ann Surg. 2010;252(2):292-8.

7. Yamamoto S, Kawahara K, Maekawa $\mathrm{T}$ et al. Minimally invasive esophagectomy for stage I and II esophageal cancer. Ann Thoracic Surg. 2005;80: 2070-5.
8. Akaishi T, Kaneda I, Higuchi $\mathrm{N}$ et al. Thoracoscopic en bloc total esophagectomy with radical mediastinal lymphadenectomy. J Thorac Cardiovasc Surg. 1996;112:1533-41.

9. Curran AJ, Gough DB, Muircheartaigh OI, Keeling P (1992) Transhiatal esophagectomy in the management of advancedesophageal carcinoma. J R Coll Surg Edinb. 37:225-8. 